\title{
CONFLITOS E DESAFIOS ENTRE A REGIONALIZAÇÃO DO SANEAMENTO BÁSICO, A GOVERNANÇA DA ÁGUA E A MACROMETRÓPOLE PAULISTA
}

\author{
Rafael Alves ORSI ${ }^{1}$ \\ Juliano Costa GONÇALVES ${ }^{2}$ \\ Erica PUGLIESI ${ }^{3}$ \\ Dayana ALMEIDA ${ }^{4}$
}

RESUMO: A macrometrópole paulista (MMP) é uma proposta de regionalização com 174 municípios fundamentada em questóes e dinâmicas econômicas para pensar estratégias de planejamento e gestão do território. A gestão da água no Estado de São Paulo estruturada em uma gestão descentralizada e participativa delimitou os limites geográficos de aplicaçáo de políticas que visam o equilíbrio ecológico dentro de bacias hidrográficas. Uma terceira lógica de regionalização surgiu para implementar as políticas do saneamento básico, Lei no 14.026/20 (Novo Marco Regulatório do Saneamento). Este artigo busca compreender as regionalizações da MMP, da gestão dos recursos hídricos e no novo marco de saneamento básico, focando nos instrumentos de planejamento, gestão socioambiental e governança da água, utilizando revisão

\footnotetext{
1 Universidade Estadual Paulista (UNESP), Faculdade de Ciências e Letras, Araraquara - SP - Brasil. Professor Associado no Programa de Pós-graduação em Ciências Sociais. ORCID: https://orcid.org/0000-0002-6898-7820. rafael.a.orsi@unesp.br.

2 Universidade Federal de São Carlos (UFSCar), Departamento de Ciências Ambientais, São Carlos - SP - Brasil. Professor Associado no Programa de Pós-Graduação em Ciências Ambientais. ORCID: https://orcid.org/00000002-6836-7154.juliano@ufscar.br.

3 Universidade Federal de São Carlos (UFSCar), Departamento de Ciências Ambientais, São Carlos - SP - Brasil. Professora Associada no Programa de Pós-Graduação em Ciências Ambientais. ORCID: https://orcid.org/00000003-4688-1387. epugliesi@ufscar.br.

4 Universidade Federal de São Carlos (UFSCar), Departamento de Ciências Ambientais, São Carlos - SP - Brasil. Pós-doutoranda. Suporte pelo processo no 2019/19640-6 na Fundação de Amparo à Pesquisa do Estado de São Paulo (FAPESP). ORCID: https://orcid.org/0000-0001-7709-9297. almeida.dds@gmail.com.
} 
bibliográfica e documental. As regionalizaçóes possuem recortes espaciais divergentes que sobrepostos enfraquecem o planejamento, a gestão e governança da água, devido, principalmente, ao modelo de regionalização do saneamento do Estado de São Paulo.

PALAVRAS-CHAVE: gestão dos recursos hídricos; saneamento; planejamento.

\title{
CONFLICTS AND CHALLENGES BETWEEN THE REGIONALIZATION OF BASIC SANITATION, WATER GOVERNANCE AND THE PAULISTA MACROMETROPOLIS
}

\begin{abstract}
The São Paulo macrometropolis (MMP) is a proposal for regionalization covering 174 municipalities based on economic issues and dynamics aiming at strategic planning and territorial management. The management of water resources in the state of São Paulo delimited the geographic limits of policies that aim at the ecological balance within hydrographic basins, relying on decentralized and participatory management. The third logic of regionalization emerged to implement sanitation policies, Law no 14.026/ 20 (New Sanitation Regulatory Framework). The objective of this article is to understand the regionalization proposed through the literature concerning the MMP and the management of river basins and by reviewing the documents on sanitation. Regionalizations have divergent spatial cutouts that overlap and weaken the planning, management, and governance of water, mainly due to the model of regionalization of sanitation in the State of Sáo Paulo.
\end{abstract}

KEYWORDS: water resources management; sanitation; planning.

\section{Introdução}

Basta alguns apontamentos iniciais sobre a macrometrópole paulista (MMP) para evidenciar seu dimensionamento, magnitude e importância para a economia paulista e brasileira de maneira geral. São 174 municípios, com um PIB de R \$ 1,07 trilhóes (15,28 \% do PIB nacional) (SEADE, 2018; IBGE, 2018), população estimada de 33,4 milhôes de pessoas (15,69\% da população brasileira) (IBGE, 2021), alta concentração de comércio e serviços, malha viária altamente concentrada e desenvolvida, elevada produção industrial dentre outros fatores de grande relevância social e econômica. Porém, há de se destacar as grandes desigualdades apresentadas na região, a concentração de renda, a falta de 
acesso à habitação, poluição em diferentes categorias, todos apontando para uma dimensão de fragilidade da MMP. Os números são vultosos e, se por um lado, mostram a potência da macrorregião, por outro apontam os desafios inerentes a esta estrutura de grande magnitude.

Dentre tais desafios, aqui destacam-se os ambientais em uma região de altíssima concentração produtiva, populacional, de consumo e de alto impacto ambiental, vinculados à formação urbano-industrial. Sem aludir a simplificação ou a linearidade das açôes, é válido destacar que os desafios estão tanto na origem, na disponibilidade dos recursos básicos para a provisão das necessidades da macrorregiáo como no correto manejo e destinaçáo dos subprodutos gerados em seus processos. Tais questôes estão envolvidas no contexto de uma região que apesar da grande riqueza e dinamicidade comporta grandes bolsóes de pobreza, populaçóes em condiçóes socioeconomicamente vulneráveis e grandes desigualdades sociais e ambientais.

Frente a esta situação, desde a década de 1990 do século XX, há formas de gestão que buscam ampliar o conjunto de atores que participam das decisóes que afetam o acesso, uso e distribuição de recursos ambientais (BURSZTYN; BURSZTYN, 2012; JACOBI; SINISGALLI, 2012). Estas formas de gestão são conhecidas como governança, conceituada como "regras, processos e comportamentos que afetam a forma como os poderes são exercidos em particular com referência a abertura, participação, responsabilização (accountability), efetividade e coerência (EUROPEAN COMMISSION, 2001). A governança ambiental é uma delimitação temática, sendo tal termo utilizado quando a governança se refere "à esfera do desenvolvimento sustentável e das políticas ambientais" (FONSECA; BURSZTYN, 2009, p. 20). Neste sentido, governança ambiental é o

[...] conjunto de práticas envolvendo instituiçóes e interfaces de atores e interesses, voltados à conservação da qualidade do ambiente natural e construído, em sintonia com os princípios da sustentabilidade. Envolve regras estabelecidas (escritas ou não) e esferas políticas mais amplas do que as estruturas de governo" (BURSZTYN; BURSZTYN, 2012. p. 165).

Neste trabalho a abordagem de governança está direcionada à água, que é elemento natural desvinculado de uso, logo mais amplo do que recurso hídrico o qual sempre traz como referência a algum tipo de uso.

Uma importante alteração dentro da governança da água está relacionada à remodelação do marco legal do saneamento básico com a promulgação da Lei no 
14.026, de 15 de julho de 2020, que estrutura um novo modelo de governança do saneamento e traz alteraçóes relevantes na base legal, entre elas: (i) a Lei $\mathrm{n}^{\circ}$ 11.445, de 5 de janeiro de 2007 (Lei de Saneamento); (ii) a Lei no 13.089, de 12 de janeiro de 2015 (Estatuto da Metrópole), para estender seu âmbito de aplicação a unidades regionais e outras alteraçôes; (iii) a Lei no 9.984, de 17 de julho de 2000, para atribuir à Agência Nacional de Águas e Saneamento Básico - ANA competência para instituir normas de referência para a regulação dos serviços públicos de saneamento básico; e (iv) a Lei no 11.107, de 6 de abril de 2005, para vedar a prestação por contrato de programa dos serviços públicos de que trata o art. 175 da Constituição Federal (Lei dos Consórcios Públicos) (ASSEMAE, 2021; TCESP, 2021).

Essas alterações modificaram substancialmente as condiçóes jurídico-econômicas dentro das quais os gestores municipais precisam tomar decisóes políticas e administrativas acerca do planejamento, da estruturação e, em última instância, do provimento dos serviços de saneamento básico em suas municipalidades (ASSEMAE, 2021). Um dos aspectos que tem gerado maior impacto e questionamentos é o modelo de regionalização de serviços de saneamento básico, objeto de regulamentaçóes estaduais para sua efetivação.

Tendo em vista esses apontamentos, objetiva-se com este artigo trazer para o debate o descompasso existente na governança ambiental entre o modelo de regionalização adotado pelo Estado de Sáo Paulo - no escopo do novo marco regulatório do saneamento básico - e a proposta de macrorregionalização desenvolvida pela EMPLASA (Empresa Paulista de Planejamento Metropolitano), conformando a MMP. Trata-se de uma pesquisa exploratória com a qual busca-se olhar, primeiramente, para o plano dessas regionalizaçóes como instrumentos de planejamento e gestáo e compreender se o recorte setorial do saneamento básico justifica tais distanciamentos na regionalização. Para o desenvolvimento da pesquisa buscou-se compreender as regionalizaçôes propostas através da literatura no caso da MMP e da gestáo de bacias hidrográficas e com a revisão de documentos sobre o saneamento básico, de tal forma que a sobreposição represente além da base territorial - claramente divergentes - mas também a funcionalidade operativa de tais instrumentos de planejamento e gestâo, sobretudo no que diz respeito às questóes socioambientais e a governança ambiental.

Para tanto estruturou-se o artigo em quatro partes. Na primeira delas discute-se brevemente a formação da macrometrópole e é apresentada a MMP em linhas gerais. Na segunda parte, buscando situar a debate no campo da governança ambiental, são destacados elementos pertinentes para a análise das regionalizaçôes. No terceiro e no quarto, o artigo volta-se para o marco legal 
do saneamento básico e sua regionalização no Estado de São Paulo e trata-se de voltar o olhar para as aproximaçóes e distanciamentos presentes entre ambas regionalizaçóes.

\section{Breve Contextualização sobre a macrometrópole}

Na década de 1970, Lefebvre (2008) em seu livro a Revolução Urbana, traz um par dialético na leitura do processo de produção do espaço urbano. Para o autor, a cidade implode e, ao mesmo tempo, explode. Sua implosão está na ruína de suas características internas até então presentes, com suas imagens, sentidos e movimento. Já sua explosão refere-se ao espraiamento, a magnitude, a dimensão avultada que se desenha com a evolução urbana. Este duplo movimento precede o momento crítico do urbano, cujos papéis das cidades são redesenhados na sociedade urbana. A urbanização induzida pela sociedade industrial passa a ser a indutora de transformaçóes sociais profundas dentro das estruturas da sociedade. Aqui apontando, portanto, para a urbanização da sociedade, empiricamente marcada pela concentração das dinâmicas sociais e econômicas nas cidades, mas ampliada enquanto modo de vida, para toda sociedade, entendida como sociedade urbana. A respeito da relação entre a compreensão empírica da urbanização planetária e do dimensionamento do urbano, em sua perspectiva teórica e conceitual, Brenner (2014) e Brenner e Schmid (2016) apresentam importantes distinçôes e análises.

Quando o olhar se volta para a formação das macrometrópoles, obviamente, a concretude da sociedade urbana apresenta-se em escala e magnitudes expressivas. Como já apresentado na introdução deste artigo, no caso da MMP são 174 municípios incluindo a cidade mais populosa do hemisfério sul, correspondendo cerca de $15,7 \%$ de toda população brasileira. Considerando a proposta de regionalização feita por Santos e Silveira (2008), que divide o Brasil em quatro grandes regióes (Norte, Nordeste, Centro-Oeste e Concentrada) a qual está assentada na desigual distribuição de objetos técnicos e fluxos pelo território e referenciada na abordagem teórica-metodológica do meio técnico-científico-informacional, é possível se dizer que a MMP é a área core da região concentrada. Tal entendimento se dá pela alta concentração e, portanto, alta dinamicidade na porção sudeste e sul do Brasil, classificada pelos autores supracitados como região concentrada, na qual a MMP se destaca em múltiplas dimensôes. Ainda considerando Santos (1997), ao tratar de zonas luminosas e zonas opacas, representando contrastes entre riqueza e pobreza, dinamicidade e lentidão, desenvolvimento e subdesenvolvimento, uma analogia de grande 
relevância e elucidativa poderia ser a de uma nebulosa. Lencioni (2015), sem querer buscar definiçóes conceituais para a terminologia, utiliza-se do termo nebulosa para tratar da macrorregião envolvendo regióes metropolitanas de São Paulo e Rio de Janeiro. De maneira interessante, a utilização da analogia remete a todo um complexo de relaçôes dispersas, porém articuladas, com geometrias de poder distintas, refletidas em graus de desenvolvimento desigual, mas combinados dentro de uma região de grande dimensão escalar. Tomando a nebulosa como metáfora, claramente são evidenciadas tais assimetrias, visíveis no contraste entre os minúsculos pontos de brilho fraco, quase apagados e o destaque das áreas mais brilhantes. Em que pese as distinçóes, é importante entender a região em sua totalidade, compreendendo que mesmo com a dispersão, a aglutinação e a articulação são os elementos chave para compreensão desse espaço como uma região (macrorregião) e não apenas como uma área, na qual a articulação não é elemento relevante. Como destaca a autora,

[...] a chave para se compreender os limites da dispersão reside no exame da integração na dispersão. Só assim é possível compreender que só na aparência os fragmentos dáo ideia de pontos isolados. Cada fragmento é parte de uma totalidade. Uma nebulosa urbana, seja ela considerada uma megalópole, uma metápole ou uma cidade-regiāo, constitui uma totalidade composta de fragmentos de uma unidade. É a integraçáo entre as partes do todo que se constitui na chave para apreensão dos limites dessas grandes extensôes urbanas que cada vez mais se afiguram no mapa do mundo (LENCIONI, 2015, p.9).

Aplicando-se à MMP o mesmo exercício feito por Lencioni nas regióes metropolitanas de São Paulo e Rio de Janeiro, obtém-se uma imagem bastante interessante dos contrastes de luminosidade e opacidade na macrorregiáo, no entanto, o que chama a atenção é a forte luminosidade da área (Fig. 1). 
Figura 1 - Imagem noturna da Macrometrópole Paulista (Visible Infrared Imaging Radiometer Suite (VIIRS) Day/Night Band)

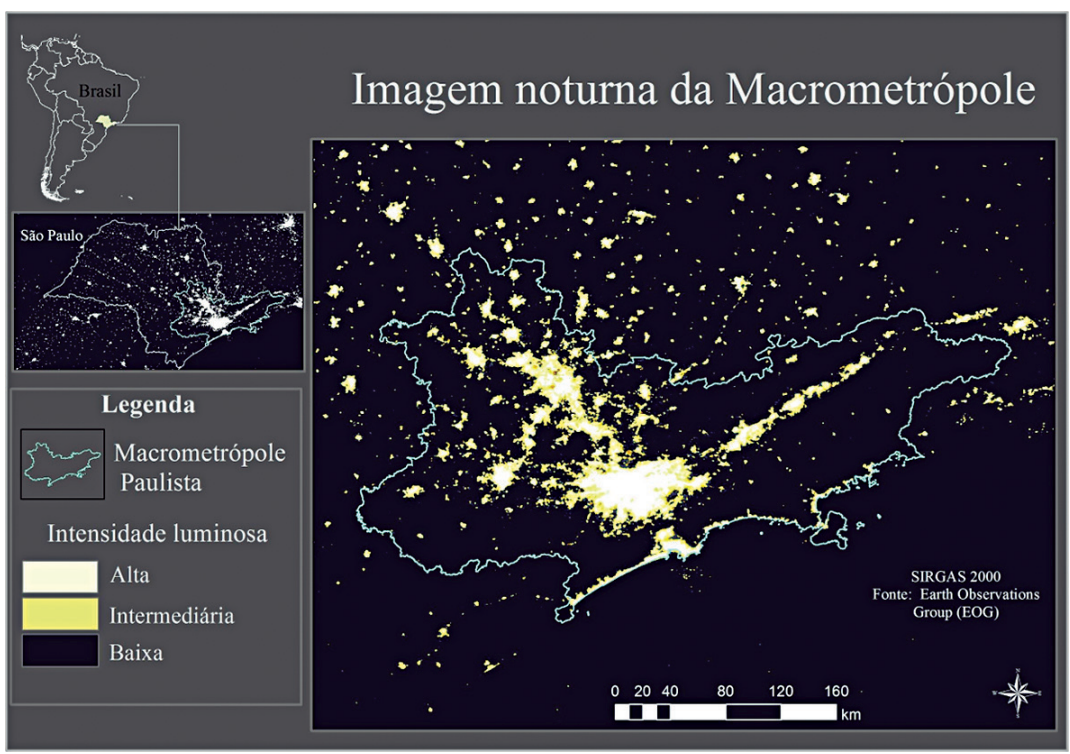

Fonte: Elaboração própria com base em dados públicos do Earth Observations Group (EOG $)^{5}$.

Tratada pioneiramente por Vilmar Faria, como apresentado por Tavares (2018), o termo macrometrópole foi forjado no bojo das discussôes da geografia econômica, apresentando-se como instrumental analítico territorial da divisão social do trabalho. De tal maneira, as discussões a respeito das migraçóes, articulaçóes territoriais e produção foram elementos centrais de preocupação. Entendendo a MMP formada em um raio de $120 \mathrm{~km}$ a partir da capital paulista, Vilmar Faria traz elementos importantes para a classificação da região. Tavares (2018) também destaca o importante trabalho de Sandra Lencioni nos anos 2000 sobre as reestruturaçóes produtivas e as novas configuraçóes desta região, buscando trazer o conceito de cidade-regiáo para interpretação deste novo processo de produção do espaço. Mantendo o olhar para pesquisas do início do século XXI, Tavares (2018) destaca os trabalhos de Meyer, Grostein e Biderman (2004), no qual a leitura da metrópole expandida ou macrometrópole se dá na identificação de clusters de produção, entendendo as novas divisóes do trabalho na região e a dispersão das plantas produtivas para fora da região metropolitana de São Paulo. A análise da MMP se fundamenta em questôes e dinâmicas econô-

Disponível em: https://payneinstitute.mines.edu/eog/. Acesso em: 4 fev. 2022. 
micas. Passando por questôes basilares na formação da MMP, o autor cita Théry (2007), o qual organiza a sua análise em eixos estruturantes da MMP, destacando a importância da malha rodoviária na articulação da região. Trazendo a importância social da MMP, para além das questôes geométricas que possam envolver o debate, Tavares (2018), destaca os esforços da EMPLASA no início da segunda década deste século, para o aprimoramento das definiçôes teóricas e conceituais da MMP, tendo o conceito de cidade-regiáo como importante referencial.

Neste breve compilado, referenciado em Tavares (2018), claramente as concepçôes teórico-metodológicas e conceituais que permeiam a discussão sobre a MMP fundamentam-se na dinâmica da produção e reprodução capitalista e sua dimensão espaço-temporal que dinamiza e reconfigura o território. Com distintas concepçôes teóricas e conceituais, projetando-se em delimitações territoriais também distintas, articulam-se e sustentam a possibilidade de um pensamento pragmático sobre esta vasta e complexa região. No bojo dessas discussóes, questôes fundamentais são apresentadas, tais como policentralidade, governança multiescalar, políticas multiníveis, todas apontando para a complexidade náo apenas das definições conceituais, metodológicas e sua base territorial empírica, mas sobretudo para os aparatos de planejamento e gestáo do território. Leonel, Zioni e Momm (2019), analisando a regionalização da MMP elaborada pela EMPLASA e a desenvolvida pelo DAEE, demonstram que seus perímetros não apresentam similaridades o que, para os autores do estudo, evidencia o caráter fluido dos limites da MMP, como é apontado, inclusive, pela própria EMPLASA no PAM - Plano de Ação da Macrometrópole Paulista. É válido chamar a atenção também para o fato de que a fluidez destacada caminha pari passu com a aplicação de recortes setoriais e suas especificidades. No estudo desenvolvido pelos autores supracitados, o recorte foi dado observando o Plano Diretor de Aproveitamento de Recursos Hídricos para a Macrometrópole Paulista, ou seja, ainda que não descolado de todo o contexto da MMP, os interesses apontavam para objetivos específicos. Aqui parece haver um desafio significativo no campo do tratamento da MMP como instrumental de planejamento e gestão territorial: a análise da especificidade sem, contudo, subverter a compreensão e o potencial da macrorregionalização como instrumento analítico, de planejamento e gestão.

Ao se voltar o olhar para o planejamento e gestão ambiental e a governança socioambiental são evidentes os desafios da intersetorialidade e os riscos do tratamento fraturado. É imperativo a compreensão articulada da problemática socioambiental identificando seus agentes, articulaçóes e dinâmicas. Como destaca Orsi (2016), os problemas socioambientais como uma questão política exige a compreensão de múltiplas escalas: do global, difuso, de difícil compreensão 
direta com limitada clareza das relações causais até o local, espaço da vida cotidiana, lugar de realização da vida e percepção mais direta de todas as dinâmicas e dos problemas enfrentados. Passando, obviamente, pela escala regional em diferentes escalonamentos e características. A construção da governança passa por estes movimentos transescalares, apontando para importância territorial de sua construção. No entanto, é necessário inserir mais uma camada sobre esta discussão, já que a dinâmica da natureza apresenta movimentos, articulaçôes e espacialidades que independem da construção política do território, porém recaindo fortemente nas formas de planejar, gerir, perceber e construir territorialidades. Se na definição da MMP projeta-se para uma regionalização que possa ter capacidade instrumental de operacionalização de políticas públicas de diferentes ordens com a criação de governança territorial, parece claro que estes desafios devem ser enfrentados e, especificamente na dimensão ambiental, o próprio PAM mostra-se tímido. Leonel, Zioni e Momm (2019), ao analisar o texto sobre os eixos estratégicos de desenvolvimento, apontam que o termo sustentabilidade e seus análogos apresentam pouca expressão no documento da EMPLASA.

Ainda que se possa ter definiçôes abertas em relação aos limites territoriais da MMP, lembrando que não há uma institucionalização juridicamente formal da área, o desenvolvimento de uma governança ambiental para regiáo passa pelo desafio da intersetorialidade e de uma expressão de base territorial se que operacional para o fortalecimento da governança e execução das políticas públicas.

\section{Desafios para a governança da água}

A governança ambiental é difundida na literatura especializada como elemento essencial para estabelecer um processo de gestão ambiental mais eficiente, transparente e justo, com pluralismo político com a inclusão dos atores sociais interessados e afetados pelas decisóes tomadas (FONSECA; BURSZTYN, 2009; BENSON; JORDAN, 2017). A governança ambiental tem foco na noção de poder social para mediar as relaçóes entre Estado, Sociedade Civil, os mercados e o meio ambiente, se inserindo em um "plano de relaçóes de poder e do fortalecimento de práticas de controle social e constituição de públicos participativos" (JACOBI; SINISGALLI, 2012, p. 1472). O foco deste artigo será a discussão da governança da água doce, subárea da governança ambiental. A Governança da água faz referência à gestáo da água em seus sistemas políticos, legais, econômicos e administrativos (UN; WWAP, 2009). 
No Estado de São Paulo a Lei Estadual n 7663/91 estabeleceu a Política Estadual de Recursos Hídricos (PERH), bem como o Sistema Integrado de Gerenciamento de Recursos Hídricos, que influenciaram a Lei Federal $\mathrm{n}^{\circ}$ 9.433/97 que institui a Política Nacional de Recursos Hídricos (PNRH) e cria o Sistema Nacional de Gerenciamento de Recursos Hídricos (SINGREH). A PERH, em consonância com a PNRH, estabelece um modelo de governança da água para o Estado de São Paulo que deverá atender aos seguintes princípios básicos:

I - gerenciamento descentralizado, participativo e integrado, sem dissociação dos aspectos quantitativos e qualitativos e das fases meteórica, superficial e subterrânea do ciclo hidrológico;

II - a adoção da bacia hidrográfica como unidade físico-territorial de planejamento e gerenciamento;

III - reconhecimento do recurso hídrico como um bem público, de valor econômico, cuja utilização deve ser cobrada, observados os aspectos de quantidade, qualidade e as peculiaridades das bacias hidrográficas; [...] (SÃO PAULO, 1991, p.1).

A gestão descentralizada na legislação tem uma dupla dimensão, qual seja: i) administrativa com transferência de funções específicas de órgãos do aparelho estatal; e, ii) territorial, com uma nova esfera de poder decisório o Comitê de Bacia (que opera com uma composição tripartite com representação de sociedade civil, estado e municípios) (CAMPOS; FRACALANZA, 2010).

A utilização da bacia hidrográfica como Unidade de Gerenciamento de Recursos Hídricos surge da ideia de que os limites geográficos de aplicação de políticas que visam o equilíbrio ecológico têm que ser os da bacia hidrográfica, ou seja, o espaço territorial determinado e definido pelo escoamento, drenagem e influência da água, do ciclo hidrológico na superfície da Terra, e não aquelas divisóes políticas que não comportam a dinâmica natural. Isso significa que o próprio Estado cria uma nova territorialidade para pensar políticas de desenvolvimento. Essa nova territorialidade chama-se Unidade de Gerenciamento de Recursos Hídricos (UGRHI). As vantagens dessa nova unidade territorial estão na visão interdisciplinar e sistêmica de um sistema natural, que está submetido a impactos e usos múltiplos e o entendimento das interdependências de processos atuantes numa bacia hidrográfica. 
Para garantir a exequibilidade dos princípios da Lei ${ }^{\circ} 7663 / 91$, foi criado do Sistema Integrado de Gerenciamento de Recursos Hídricos (SIGRH) que visa o estabelecimento do gerenciamento dos recursos hídricos e foi estruturado da seguinte forma: 1) estruturas deliberativas: Conselho Estadual de Recursos Hídricos (CRH) e Comitês de Bacia Hidrográficas (CBHs); 2) estrutura técnica: Comitê Coordenador da Política Estadual de Recursos Hídricos (CORHI); e, 3) estrutura financeira: Fundo Estadual de Recursos Hídricos (FEHIDRO) (GARCIA; VALENCIO, 2003). Assim, a partir da estruturação do SIGRH, com a Lei no 9.034, o Estado de São Paulo foi dividido em 22 Unidades de Gerenciamento de Recursos Hídricos (UGRHIs) e foram criados os comitês de bacia hidrográfica para cada uma das UGRHIs. As UGRHIs foram formadas por uma "combinação original que articula uma representação da natureza e uma representação social, ou seja, tanto a natureza quanto a sociedade são representados parcialmente no sistema de gestão proposto e implementado" (RIBEIRO, 2009, p. 128).

Antes das políticas de Recursos Hídricos (estaduais e federais) a gestão de recursos hídricos era bastante fragmentada em diferentes setores (ministérios, secretarias, departamentos) responsáveis por políticas e execução de açôes em áreas como: energia elétrica, agricultura irrigada, saneamento, preservação ambiental, entre outros. Boa parte destas organizaçóes existe com atuaçóes que pouco alinhadas. Uma forma de integrar as açóes desses setores são os Planos de Recursos Hídricos, que visam orientar e viabilizar a implementação das políticas de recursos hídricos no território e devem ser elaborados pelas bacias hidrográficas, pelos Estados e pelo país. Contudo, no Estado de São Paulo, o Plano de Bacia tem caráter indicativo que "não pode ser imposto nem estabelecer prioridades às agências públicas e municipalidades" e o mesmo ocorre com o "Comitê de Bacia que não tem um poder executivo" (CAMPOS; FRACALANZA, 2010, p. 374).

Vários problemas também são relatados nas estruturas que deveriam promover participação social, como dificuldade de incorporar "os grupos sociais normalmente excluídos dos mecanismos tradicionais de deliberação" (JACOBI; SINISGALLI, 2012, p. 1472-1473). A dificuldade de alguns grupos sociais para compreender um discurso muito técnico também pode ser um elemento que restringe a participação ao mesmo tempo em que consolida outros grupos sociais mais afeitos ao discurso técnico (FONSECA; BURSZTYN, 2009).

Contudo, o maior desafio da governança ambiental, em geral, está 
[...] em sua implementação, uma vez que o núcleo do sistema político nacional persiste no seu apego quase fanático ao crescimento econômico (cf. Viola 1998-1999), além de ser extremamente vulnerável (ou simpático, para dizer o menos) aos poderosos lobbies que rondam a formulação de políticas públicas no país (CAVALCANTI, 2004, p. 6).

Câmara (2013, p. 142) argumenta que a governança ambiental precisa de um "conhecimento mais aprofundado da natureza das relaçóes institucionais e socioculturais envolvidas no uso de recursos naturais" para compreender fracassos e insucessos desta mesma governança em busca de uma política ambiental comprometida com a sustentabilidade. Neste sentido, diferentes propostas coexistentes que apresentam rupturas na compreensão do planejamento e gestão ambiental, neste caso particular das bacias hidrográficas e do saneamento - objeto deste artigo, podem representar entraves institucionais, normativos e operacionais no sentido de fortalecer a governança ambiental. $\mathrm{O}$ marco regulatório do Saneamento Básico, apresentado a seguir, nos coloca diante de tais rupturas, sobretudo em seu desdobramento físico-territorial na proposta operacional paulista.

\section{Novo marco regulatório do saneamento básico - regionalização para concessão do serviços de gestão}

O saneamento básico é tradicionalmente associado aos serviços de abastecimento de água potável e de esgotamento sanitário, porém, no Brasil, o saneamento básico compreende o conjunto de serviços públicos, infraestruturas e instalaçóes operacionais dos serviços de limpeza urbana e o manejo de resíduos sólidos e ainda a drenagem e manejo das águas pluviais urbanas.

Ao considerarmos que o saneamento é definido na Constituição Federal como um serviço de interesse local, a competência para a regularização, organização e prestação dos serviços é exclusiva dos Municípios e do Distrito Federal (art. 23, IX c/c art. 30, inc. I e V/CF). ${ }^{6}$ Estado e Municípios que compartilham instalaçóes operacionais integrantes de regiôes metropolitanas, aglomeraçóes urbanas e microrregióes - instituídas por lei complementar estadual - poderão exercer a titularidade conjunta no caso de interesse comum (TCESP, 2021).

No que concerne à prestaçáo de serviços, esta pode ser prestada diretamente pela municipalidade - por meio dos seus próprios órgáos - , ou pode ser pres-

\footnotetext{
${ }^{6}$ Um serviço de interesse local é compreendido como aquele que está circunscrito e afeta os interesses de uma municipalidade e são, portanto, de sua exclusiva competência.
} 
tada indiretamente, quando ocorre a transferência da execução dos serviços para uma outra pessoa jurídica, como uma autarquia, entidade paraestatal, empresas públicas ou sociedades de economia mista, ou, ainda, concede os serviços para empresas privadas, caracterizando, em todos os casos, uma gestão descentralizada (ASSEMAE, 2021). Os serviços podem ainda ser delegados por outorga para entes da administração pública direta e indireta do titular, e por concessão mediante licitação prévia - para entes externos. A partir da promulgação da lei dos consórcios públicos (Lei no 11.107) em 2005, a prestação dos serviços pôde se dar também por meio de contrato de programa.

O Estatuto da Metrópole define o contrato de programa como um instrumento jurídico de cooperaçáo interfederativa que permite ao titular do serviço público delegar a prestação do serviço a um ente que não participa de sua administração, mas que, por outro lado, integra a administração de um outro ente federativo (Estatuto da Metrópole, art. 9º, inc. VIII). Neste sentido, são amplamente celebrados contratos de programa com empresas estaduais de saneamento básico para delegar a prestação do serviço público, sem a realização de licitação prévia (SOUZA, 2020). Uma vez evidenciada a viabilidade de ganhos de escala e escopo na conjunção de esforços com outros entes federados, a municipalidade - no exercício de sua autonomia municipal - pode estabelecer uma gestão associada dos serviços junto a outros municípios.

O Novo Marco Regulatório do Saneamento - Lei no 14.026/20 - dentre outras alteraçóes refletidas em um novo modelo de governança proposto, veda expressamente a celebração de contratos de programa e estabelece como diretriz a formação de blocos de municípios para posterior concessão dos serviços (TCESP, 2021) condicionando a estes o acesso a recursos públicos federais e financiamentos com recursos da União ou com recursos geridos ou operados por órgãos ou entidades da União (BRASIL, 2020; SOUZA, 2020). Neste sentido, criou uma outra figura chamada prestação regionalizada.

Embora apresente sentido próximo à gestão associada, não se relaciona a esta, pois a prestação regionalizada configura-se como modalidade de prestação integrada dos serviços públicos de saneamento básico em determinada região cujo território abranja mais de um Município. Deste modo, enquanto gestão associada caracteriza-se por ser a associação de entes federados para a prestação conjunta de um serviço público, a prestação regionalizada apresenta-se como a prestação do serviço em mais de um Município e de forma independente. Neste aspecto, uma vez criados os blocos de municípios, é realizada a concessão dos serviços. 
A justificativa da regionalização da prestação dos serviços se dá no ganho de escala pelas metas de universalização de $99 \%$ da população com água potável, 90\% da população com coleta e tratamento de esgotos e metas quantitativas de não intermitência, perdas e tratamento, tendo como data limite para atingir tais metas a data de 31 de dezembro de 2033. O argumento se constrói, ainda, na elaboração dos Planos de Saneamento à nível regional, sobrepondo os planos municipais, sendo permitido o apoio técnico dos prestadores de serviços (SÃO PAULO, 2021b).

No bojo da Lei de Saneamento, a prestação regionalizada pode ser realizada em três hipóteses: (i) região metropolitana, aglomeração urbana ou microrregião: agrupamento de Municípios limítrofes, instituída pelo Estado mediante lei complementar $\left(\$ 3^{\circ}\right.$, art. $\left.25, \mathrm{CF}\right)$, nos termos do Estatuto da Metrópole; (ii) unidade regional de saneamento básico: agrupamento de Municípios não necessariamente limítrofes, instituída pelo Estado mediante lei ordinária para (i) atender adequadamente às exigências de higiene e saúde pública, ou (ii) para dar viabilidade econômica e técnica aos Municípios menos favorecidos; e iii) bloco de referência: agrupamento de Municípios não necessariamente limítrofes, estabelecido pela Uniâo e formalmente criado por meio de gestáo associada voluntária dos titulares.

No Estado de São Paulo, a regionalização dos serviços de saneamento foi estabelecida na Lei Estadual no 17.383/2021 - tramitada em regime de urgência com a criação de quatro Unidades Regionais de Serviços de Abastecimento de Água Potável e Esgotamento Sanitário (URAE), que são: i) Sudeste (com 370 municípios); ii) Centro (com 98 municípios); iii) Leste (com 35 municípios); e, iv) Norte (com 142 municípios), como pode ser observado na Fig. 2. No escopo da Lei, náo foram considerados os componentes de limpeza urbana e manejo de resíduos sólidos, drenagem e manejo das águas pluviais urbanas - que também integram os serviços públicos de saneamento básico brasileiro. 
Figura 2 - Unidades Regionais de Serviços de Abastecimento de Água Potável e Esgotamento Sanitário de São Paulo

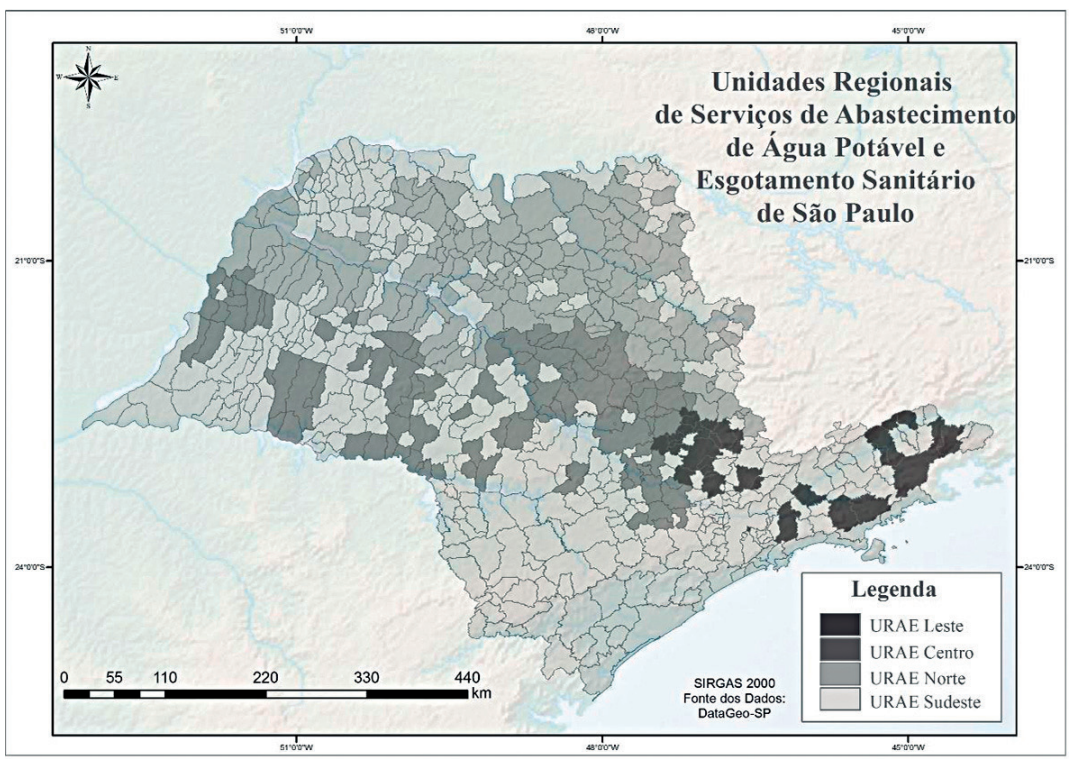

Fonte: Elaboração própria com base em dados públicos disponíveis em DataGeo - $\mathrm{SP}^{7}$.

O modelo de regionalização estabelecido no Estado de São Paulo cria um novo recorte espacial distintos daqueles apresentados pela MMP, pela UGRHIs, pelas Regiōes Metropolitanas, pelos Aglomerados Urbanos ou Regióes Administrativas, desconsiderando a governança da água e a gestão ambiental e territorial, apresentados em outros modelos de regionalização anteriormente definidos e já estabelecidos.

\section{Conflitos e desafios da regionalização do saneamento no Estado de São Paulo com a MMP e as UGRHIs}

Enquanto a divisão espacial em UGRHIs ocorreu para respeitar a "conexão entre a organização espacial dos grupos sociais e os aspectos do ambiente físico" (CARVALHO, 2020, p. 146), a lógica do recorte espacial da MMP está no adensamento urbano, na interação espacial e na integração funcional (LEONEL; ZIONI; MOMM, 2019), com um conjunto de influências vinculadas à produção social que não respeitam a subdivisão em UGRHIs (CARVALHO, 2020).

Disponível em: http://datageo.ambiente.sp.gov.br/. Acesso em: 4 fev. 2022. 
A MMP abrange total ou parcialmente onze Unidades de Gerenciamento de Recursos Hídricos (Fig. 3), englobando importantes bacias responsáveis pelo abastecimento urbano e também local de nascentes de rios de importância econômica.

Esta situação de conflito entre unidades territoriais fica mais drástica quando a lógica do recorte espacial das URAEs mostra-se conflituosa tanto com a MMP como com as UGRHIs. Assim, o planejamento e a gestão do saneamento de cada URAEs estão em discordância no desenho territorial e sua regionalização com o planejamento e a gestáo dos recursos hídricos e com o planejamento e gestão dos aspectos urbanos da MMP.

As quatro URAEs definidas pela Lei Estadual no 17.383/2021 foram delimitadas, de acordo com apresentação da SIMA (Secretaria de Infraestrutura e Meio Ambiente) com base em 4 critérios, que são: a) proximidade geográfica; b) respeito às bacias hidrográficas; c) viabilidade da prestação dos serviços e sustentabilidade econômico-financeira; e, d) o respeito aos contratos vigentes e aos atuais arranjos de prestação regionalizada dos serviços que já atendem às disposiçóes. Contudo, a análise dos dados e a regionalização resultante indicam que o critério de maior peso foi a vigência de contratos já celebrados com a SABESP, que é executora dos serviços de saneamento em 370 municípios (IAS; IDS, 2021). Todos os município com contratos com a SABESP foram colocados na URAE Sudeste criando problemas, que são:

i) fragmentação de oito das nove Regióes Metropolitanas (RMs) e Aglomeraçóes Urbanas (AU) existentes no estado; ii) divisão de parte de municípios de 18 Unidades de Gestão de Recursos Hídricos (UGRHIs) e a totalidade dos municípios de 3 UGRHIs; iii) o agrupamento deixou alguns municípios "ilhados", ou seja, estão cercados por municípios da URAE Sudeste mas fazem parte de outra URAE (IAS; IDS, 2021, p. 17). 
Figura 3 - Localização da Macrometrópole Paulista e das Unidades de Gerenciamento de Recursos Hídricos

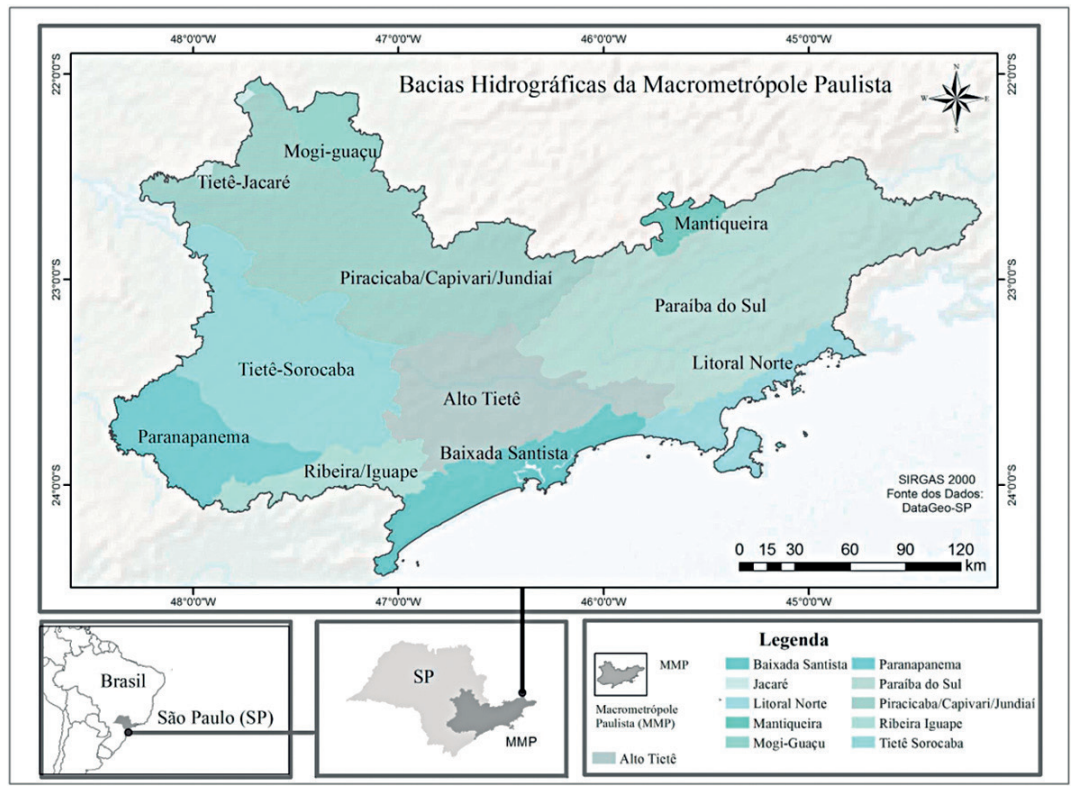

Fonte: Elaboração própria com base em dados públicos disponíveis em DataGeo - $\mathrm{SP}^{8}$

A lógica utilizada criou um recorte territorial ímpar com um "agrupamento de municípios em URAEs [que] desconsiderou as Regióes Metropolitanas e Aglomeraçóes Urbanas existentes, assim como as UGRHIs e seus respectivos Comitês e Planos de Bacias Hidrográficas" (IAS; IDS, 2021, p. 7). Ao criar municípios "ilhados" a lógica de compartilhamento das infraestruturas de saneamento presente na legislação federal fica comprometida. Considerando os limites da MMP, localizam-se as URAEs Centro com 26 municípios, Leste com 33 municípios e Sudeste com 115 municípios. Pode-se observar na Fig. 4 que os municípios pertencentes a essas unidades regionais se apresentam distribuídos de forma não homogênea. 
Figura 4 - Macrometrópole Paulista e as URAEs

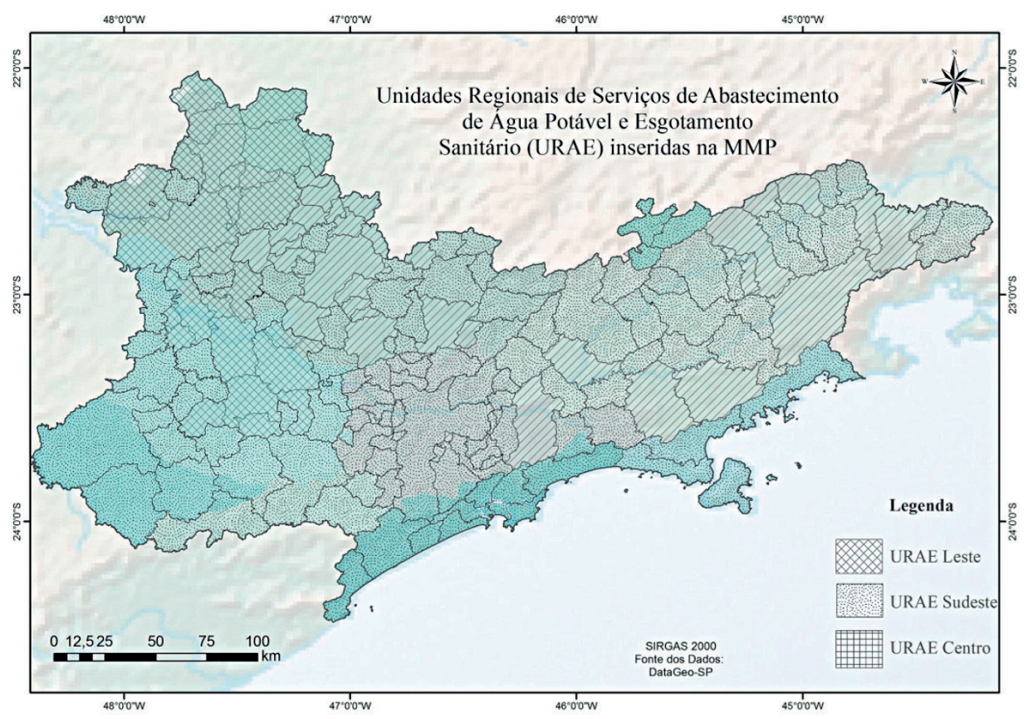

Fonte: Elaboração própria com base em dados públicos disponíveis em DataGeo - SP9 .

Sobre a criação das unidades regionais de saneamento básico, regulamentada pela Lei no $17.383 / 2021$, recai críticas relativas às formas de seu desenvolvimento, dentre as quais destaca-se a falta de um "diálogo ampliado e com critérios que considerem aspectos econômicos, ambientais e sociais" com a participação ampla e debates da proposta junto "aos municípios, aos Comitês de Bacias Hidrográficas, às instituiçóes científicas e à sociedade em geral” (IAS; IDS, 2021). Associado à falta de diálogo houve também pouca transparência na divulgação dos documentos técnicos que embasaram a criação da URAEs, bem como das notas técnicas e do parecer da consultoria jurídica elaborados pela SIMA que são citados no projeto de lei que originaram a lei supracitada (IAS; IDS, 2021).

Assim como aconteceu com a MMP e as UGRHI's, também há desarticulaçóes entre a regionalização trazida pela Lei no 17.383 e o Estatuto da Metrópole (Lei Federal n. ${ }^{\circ}$ 13.089/2015). Claramente observa-se um 'fatiamento' das RMs e das AUs, constituídas por lei complementar, e as URAEs, criadas por leis ordinárias. Para além do fato de cada uma projetar bases territoriais distintas umas das outras, atenta-se para o fato de as leis ordinárias são

9 Disponível em: http://datageo.ambiente.sp.gov.br/. Acesso em: 4 fev. 2022. 
hierarquicamente inferiores às complementares, criando inseguranças jurídicas na temática (IAS; IDS, 2021).

É importante considerar, no que concerne ao saneamento básico, que não basta os municípios serem limítrofes para que uma regionalização possa ser instituída, é necessário que se verifique o compartilhamento de instalaçóes operacionais de infraestrutura de abastecimento de água ou de esgotamento sanitário entre eles (ASSEMAE, 2021), denotando a necessidade de organização, planejamento, execução e operação de forma conjunta e integrada pelo Estado e pelos Municípios que compartilham total ou parcialmente as instalaçóes operacionais (inc. XIV, art. $3^{\circ}$, Lei de Saneamento).

Por fim, é válido salientar que o artigo 5o da a Lei no 17.383/2021 estabelece que a governança interfederativa das URAEs seguirá o modelo previsto no Estatuto da Metrópole, com a seguinte estrutura básica:

I - instância executiva composta pelos representantes do Poder Executivo dos entes federativos integrantes da respectiva - URAE;

II - instância colegiada deliberativa com representação da sociedade civil;

III - organização pública com funções técnico-consultivas;

IV - sistema integrado de alocação de recursos e de prestação de contas. (SÃO PAULO, 2021a, p.1).

A criação desta outra estrutura de governança para o saneamento, em sua organização e funcionamento, de acordo com o parágrafo acima apresentado, será decidida no âmbito das URAEs. Esta estrutura de governança paralela à governança da água e à governança das RM colabora para a fragmentaçáo da estrutura da gestão ambiental na MMP e nas UGRHIs, criando mais espaço para a governança viciosa. Vale lembrar que a governança viciosa é aquela que se constitui em um conjunto de desvios que, associados, geram conflitos e revelam contradições "entre setores da sociedade, entre organismos de governo, entre os diferentes poderes constituídos e entre as diversas formas de regulação das relaçôes entre sociedade e natureza" (BURSZTYN; BURSZTYN, 2012, p. 163). Ao se observar a regionalizaçáo trazida pelas URAEs, entende-se que diferentes conflitos na governança ambiental possam ser criados ou questóes já postas não encontrem sustentação normativa e operacional para superaçáo dos graves problemas de saneamento básico no Estado de São Paulo. 


\section{Considerações Finais}

Os processos de regionalização envolvem múltiplos fatores que articulados apontam para questôes objetivas em um processo no qual a regionalização per se não é o objetivo final, mas instrumental de planejamento e gestão. $\mathrm{Ou}$ seja, aqui há o destaque para a regionalizaçáo como parte de um processo de implantação de políticas públicas, cuja base territorial é essencial em seus desdobramentos. Obviamente, regionalizar fundamenta estudos, diagnósticos e prognósticos estruturando a própria concepção de açôes sobre o território. No entanto, o objetivo principal do artigo foi o de trazer para a discussão pontos de atrito, quando náo rupturas completas, entre formas de conceber a gestão e o planejamento do saneamento básico no Estado de Sáo Paulo, cujos esforços são mais conflitantes do que convergentes no que diz respeito à sua base territorial. As regionalizaçôes aqui apresentadas mostraram recortes espaciais divergentes que sobrepostos enfraquecem o planejamento, a gestão e governança da água, devido, principalmente, ao modelo de regionalização do saneamento do Estado de Sáo Paulo. Evidentemente, a questáo central apresentada não foi a regionalização como fim, mas os descompassos da regionalização como meios de planejamento e gestão, o que envolve, além das metodologias para a regionalização, conflitos, interesses, agentes, simetrias de poder, todos compondo e sendo parte do próprio território.

A questão de fundo apresentada no artigo traz para o primeiro plano a divisão regional para o saneamento básico no Estado de Sáo Paulo, regulamentada pela Lei no 17.383/2021. A partir desta regionalização, constata-se que há uma grande discrepância tanto no que concerne à regionalizaçáo da MMP como nas UGRHIs. Este fato mostra que, ainda que se trate da gestáo do saneamento básico - especificamente das águas -, o modelo da URAEs apresenta uma lógica distinta em sua estruturaçâo. É válido destacar que a proposta das URAEs distancia-se não apenas das UGRHIs, mas também das regiôes metropolitanas, das AU e da delimitação da MMP. Ao se olhar para a MMP, três URAES compóem este território: URAE Leste, Sudeste e Centro. Das três há descontinuidade na URAE Sudeste e a URAE Centro extrapola o território da macrometrópole.

Dessa forma, uma das questóes evidenciadas no artigo aponta para sistemas de governança ambiental divergentes no caso do saneamento básico - mais especificamente na gestão das águas. Tais distanciamentos colocam em evidência a fragilidade da governança ambiental, oscilando entre diferentes formas de compreender o território, estabelecer as divisóes e propondo institucionalidade com arranjos normativos pouco convergentes. 
É importante salientar que amparado nas Leis Federais no 11.445/2007 Lei do Saneamento - e Lei no 14.026/2020 - Marco Regulatório do Saneamento Básico - o fundamento do conjunto das políticas públicas, as quais se faz referência neste artigo, está na busca pela universalização dos serviços de saneamento básico no Brasil, os quais apresentam grande diversidade em termos de atendimento de água e esgoto. Quando se olha para contexto brasileiro de forma ampla, é notória a necessidade de um tratamento articulado e substantivo da governança para que bons resultados possam ser alcançados. De maneira particular, a MMP ainda que possa ter um quadro menos tenebroso em termos percentuais em atendimento de serviços de saneamento que outras regióes do país, é uma região cujos bolsóes de pobreza são desafiadores para a gestão do saneamento básico, no sentido da universalização e qualidade dos serviços oferecidos à população. Da mesma forma, os desafios sobre a gestão das águas na maior concentração populacional do país exigem modelos de governança que sejam coesos, articulados e comprometidos com a sustentabilidade socioambiental. Neste sentido, ainda que de caráter incipiente, procurou-se apontar com o artigo a ampliação das rupturas socioterritoriais trazidas pela URAES, apontando territorialidades com lógicas distintas de outros modelos, potencialmente trazendo prejuízos à governança do saneamento básico no Estado. De fato, destaca-se a necessidade de novos estudos neste campo, no entanto intenta-se ter trazido contribuiçóes para este campo do debate, importante para a melhoria da qualidade ambiental e de vida da sociedade.

\section{REFERÊNCIAS}

ASSOCIAÇÃO NACIONAL DOS SERVIÇOS MUNICIPAIS DE SANEAMENTO [ASSEMAE]. Regionalizaçáo de Serviços de Saneamento Básico: guia de orientação para gestores municipais sobre a prestação de serviços de saneamento básico em gestão associada. Brasília, DF: ASSEMAE, 2021. Disponível em: https://ondasbrasil. org/wp-content/uploads/2021/06/Guia-Regionalizac\%CC\%A7a\%CC\%83o-deServic\%CC\%A7os-de-Saneamento-Ba\%CC\%81sico-ASSEMAE.pdf. Acesso em: 10 out. 2021.

BENSON, D.; JORDAN, A. Environmental governance. In: INTERNATIONAL Encyclopedia of Geography. Hoboken: John Wiley, 2017. Disponível em: https://doi. org/10.1002/9781118786352.wbieg0631. Acesso em: 03 out. 2021.

BRASIL. Lei no 14.026 , de 15 de julho de 2020. Atualiza o marco legal do saneamento básico e dá outras providências. Diário Oficial da União, Brasília, 2020. Disponível 
em: http:/www.planalto.gov.br/ccivil_03/_ato2019-2022/2020/lei/l14026.htm. Acesso em: 10 set. 2021.

BRENNER, N. Teses sobre a urbanização. E-metrópolis, Rio de Janeiro, ano 05, n. 19, p. 06-26, 2014. Disponível em: http://emetropolis.net/artigo/146?name=tesessobre-a-urbanizacao. Acesso em: 21 set. 2021.

BRENNER, N.; SCHMID, C. La era urbana en debate. Eure: Revista de Estudios Urbanos Regionales, Santiago, v. 42, n. 127, p. 307-339, 2016. Disponível em: http://www.eure.cl/index.php/eure/article/view/2123/926. Acesso em: 21 set. 2021.

BURSZTYN, M. A.; BURSZTYN, M. Fundamentos de política e gestáo ambiental: caminhos para a sustentabilidade. Rio de Janeiro: Garamond, 2012.

CÂMARA, J. B. D. Governança ambiental no Brasil: ecos do passado. Revista de Sociologia e Política, Curitiba, v. 21, n. 46, p. 125-146, jun. 2013.

CAMPOS, V. N. O.; FRACALANZA, A. P. Governança das águas no Brasil: conflitos pela apropriação da água e a busca da integraçáo como consenso. Ambiente e Sociedade, Campinas, v. III, n. 2, p. 365-382, jul./dez. 2010.

CARVALHO, A. T. F. Bacia Hidrográfica como unidade de planejamento: discussão sobre os impactos da produção social na gestâo de recursos hídricos no Brasil. Caderno Prudentino de Geografia, Presidente Prudente, n. 42, v. 1, p. 140-161, jan-jun. 2020.

CAVALCANTI, C. Economia e Ecologia: Problemas da Governança Ambiental no Brasil. Revista Iberoamericana de Economía Ecológica, Rio de Janeiro, v.1, n.1, p.1-10, 2004.

EUROPEAN COMMISSION. European Governance: a White Paper. Brussels: Commission of the European Communities, 2001. Disponível em: https://ec.europa. eu/commission/presscorner/detail/en/DOC_01_10. Acesso em: 2 fev. 2022.

FONSECA, I. F. da; BURSZTYN, M. A banalização da sustentabilidade: reflexôes sobre governança ambiental em escala local. Sociedade e Estado, Brasília, v.24, n.1, 2009.

GARCIA, A. C. M. C.; VALENCIO, N. Gestão de recursos hídricos no Estado de São Paulo: obstáculos técnicos e políticos à sustentabilidade das práticas decisórias em Comitês de Bacias. In: MARTINS, R. C.; VALENCIO, N.F.L.S. (org.). Uso e Gestáo dos Recursos Hídricos no Brasil: desafios teóricos e político-institucionais. São Carlos: RiMa, 2003. v. II. p. 187-202.

INSTITUTO ÁGUA E SANEAMENTO [IAS]; INSTITUTO DEMOCRACIA E SUSTENTABILIDADE [IDS]. Desafios e riscos da implementaçáo do marco 
legal do saneamento no estado de Sáo Paulo: análise do PL 251/2021. São Paulo, jun. 2021. Disponível em: https://drive.google.com/file/d/1rAYP7CjlGYSoflctgk0FZ bumDrgWjcTH/view. Acesso em: 15 set. 2021.

INSTITUTO BRASILEIRO DE GEOGRAFIA E ESTATÍSTICA [IBGE]. Estimativas de Populaçáo 2021. Rio de Janeiro, 2021. Disponível em: https://sidra. ibge.gov.br/tabela/6579. Acesso em: 05 out. 2021.

INSTITUTO BRASILEIRO DE GEOGRAFIA E ESTATÍSTICA [IBGE]. Produto Interno Bruto - PIB. Rio de Janeiro, 2018. Disponível em: https://www.ibge.gov.br/ explica/pib.php. Acesso em: 08 out. 2021.

JACOBI, P.; SINISGALLI, P. A. A. Governança ambiental e economia verde. Ciência \& Saúde Coletiva, Rio de Janeiro, v.17, n.6, p.1469-1478, 2012.

LEFEBVRE, H. A revolução urbana. Belo Horizonte: Ed. da UFMG, 2008.

LENCIONI, S. Urbanização difusa e constituição de megarregiôes: o caso de São Paulo-Rio de Janeiro. E-metrópolis, Rio de Janeiro, ano 06, n. 22, p. 06-15, 2015. Disponível em: http://emetropolis.net/artigo/167?name=urbanizacao-difusa-e-aconstituicao-de-megarregioes-o-caso-de-sao-paulo-rio-de-janeiro. Acesso em: 21 set. 2021.

LEONEL, A. L.; ZIONI, S.; MOMM, S. Macrometrópole paulista: apontamentos sobre uma nova unidade de planejamento. In: ENANPUR, 18., 2019, Natal. Anais [...], Natal, 2019. Disponível em: http://anpur.org.br/xviiienanpur/anaisadmin/ capapdf.php?reqid=593. Acesso em: 22 set. 2021.

MEYER, R. P.; GROSTEIN, M. D.; BIDERMAN, C. São Paulo Metrópole. São Paulo: Edusp; Imprensa Oficial do Estado de São Paulo, 2004.

ORSI, R. Problemas socioambientais e a dimensão política do espaço. Geographia, Niterói, ano 18, n. 36, p. 108-127, 2016. Disponível em: http://periodicos.uff.br/ geographia/article/view/13745/8945. Acesso em: 02 jan. 2019.

RIBEIRO, W. C. Impasses da governança da água no Brasil. In: RIBEIRO, W. C. (org.). Governança da água no Brasil. São Paulo: Annablume; Fapesp; CNPq, 2009. p.111-133.

SANTOS, M. Técnica, espaço e tempo: globalização e meio técnico-científico informacional. São Paulo: HUCITEC, 1997.

SANTOS, M.; SILVEIRA, M. L. O Brasil: território e sociedade no início do século XXI. Rio de Janeiro: São Paulo: Record, 2008.

SÃO PAULO. Lei no 17.383, de 05 de julho de 2021a. Dispóe sobre a criação de unidades regionais de saneamento básico, com fundamento nos artigos $2^{\circ}$, inciso 
XIV, e 3º inciso VI, alínea "b", da Lei Federal no 11.445, de 5 de janeiro de 2007, e dá providências correlatas. Assembleia Legislativa do Estado de Sáo Paulo, São Paulo, 2021.

SÃO PAULO. Secretaria de Infraestrutura e Meio Ambiente. Regionalizaçáo Novo Marco Regulatório. São Paulo, 2021b. Disponível em: https://sigrh.sp.gov.br/public/ uploads/documents/CRH/20821/regionalizacao-marco-saneamento.pdf . Acesso em: 06 out. 2021.

SÃO PAULO. Lei no 7663, de 30 de dezembro de 1991. Estabelece normas de orientação à Política Estadual de Recursos Hídricos bem como ao Sistema Integrado de Gerenciamento de Recursos Hídricos. Assembleia Legislativa do Estado de Sáo Paulo, São Paulo, 1991.

SISTEMA ESTADUAL DE ANÁLISE DE DADOS [SEADE]. PIB Municipal: 2018. São Paulo, 2018. Disponível em: http://repositorio.seade.gov.br/dataset/pibmunicipal. Acesso em: 06 out. 2021.

SOUZA, A. C. A. O que esperar do novo marco do saneamento? Cadernos de Saúde Pública, Rio de Janeiro, v. 36, n. 12, 2020. Disponível em: https://www.scielo.br/j/ csp/a/S4RRsCRpr4XqGYwzCh5gnwz/?lang=pt. Acesso em: 05 out. 2021.

TAVARES, J. Formação da macrometrópole no Brasil: construção teórica e conceitual de uma região de planejamento. Eure: Revista de Estudios Urbanos Regionales, Santiago, v. 44, n. 133, pp. 115-134, 2018. Disponível em: https://www.eure.cl/ index.php/eure/article/view/2644/1112. Acesso em: 22 set. 2021.

THÉRY, H. Chaves para a leitura do território paulista. Confins, São Paulo, n.1, 2007. Disponível em: http://dx.doi.org/10.4000/confins.25. Acesso em: 22 set. 2021.

TRIBUNAL DE CONTAS DO ESTADO DE SÃO PAULO [TCESP]. O Novo Marco Legal do Saneamento Básico. São Paulo, 2021. Disponível em: https:// www.tce.sp.gov.br/sites/default/files/publicacoes/Manual\%20Saneamento\%20B\% C3\%A1sico\%20-\%20TCESP.pdf. Acesso em: 15 set. 2021.

UNITED NATIONS [UN]; WORLD WATER ASSESSMENT PROGRAMME [WWAP]. Water in a Changing World. Paris: UNESCO, 2009.

Recebido em: 15 de outubro de 2021

Aprovado em: 20 de outubro de 2021 